\title{
3 đầu sách tại Thư viện Trường Đại học Mở TP.HCM
}

Trung tâm thông tin thư viện

Truy cập:

Ngày 2 tháng 3 năm 2021

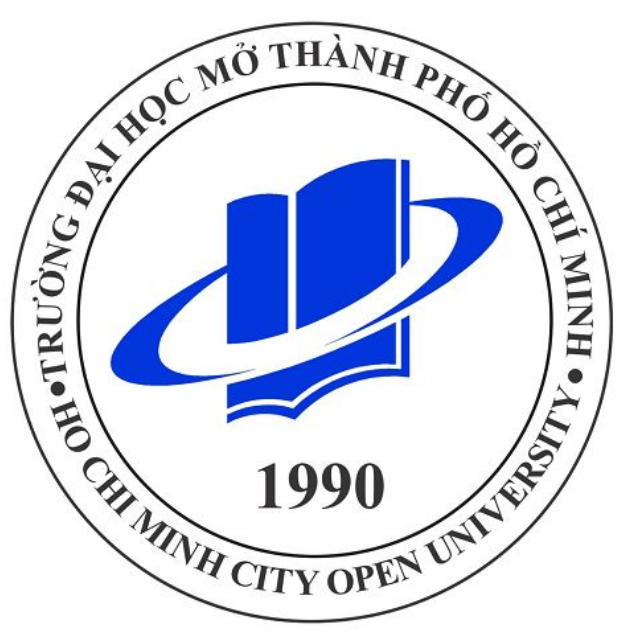

Trường Đại học Mở Thành Phố Hồ Chí Minh

Địa chỉ URL: http://thuvien.ou.edu.vn/Default.aspx?Moduleld=00000001-0000-00000000-000000000003

Ba địa chỉ sách truy cập được qua hệ thống:

1. Văn minh làm giàu \& nguồn gốc của cải; Ký hiệu xếp giá : 650.09597 / V994H6788

2. Kinh tế Việt Nam: Thăng trầm và đột phá; Ký hiệu xếp giá : 338.9597 (Kho sách Võ Văn Tần)

3. Các phương pháp toán học trong tài chính; Ký hiệu xếp giá : 650.0151

Chi tiết thông tin thư viện như trong bản các bản pdf printout từ trang Internet của thư viện HCM Open Uni bên dưới.

Thông tin trích dẫn trong phần tài liệu tham khảo. 
Bộ sưu tập :

Kho tài liệu :

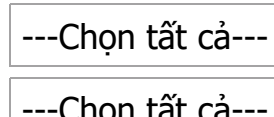

---Chọn tất cả---

Từ khóa tìm kiếm : Vương Quân Hoàng

Sắp xếp : Không sắp xếp

Hiển thị : 20

Trang : 1

11

Có 7 kết quả tìm được

\section{Nhan đề (click để xem chi tiết)}

1 Văn minh làm giàu \& nguồn gốc của cải / Vương Quân Hoàng. - In lần thứ 1. - Hà Nộ 2007. - 498tr ; $24 \mathrm{~cm}$

[Chi tiết]

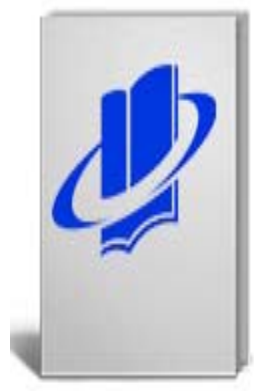

\begin{tabular}{|c|c|}
\hline Bộ sưu tập : & Sách - Giáo trình \\
\hline Tác giả chính : & Vương, Quân Hoàng , TS. \\
\hline Ngôn ngũ̃ : & Tiếng Việt \\
\hline Ký hiệu xếp giá : & 650.09597 / V994H6788 \\
\hline Lần xuất bản : & In lần thứ 1 \\
\hline Nơi xuất bản : & Hà Nội : Chính trị Quốc gia, 2007 \\
\hline Mô tả vật lý : & 498tr. ;24 cm \\
\hline Chủ đề : & $\begin{array}{l}\text { - Công ty, Văn hóa--Việt Nam } \\
\text { - Kinh doanh, Nghi thức } \\
\text { - Văn hóa--Khía cạnh kinh tế } \\
\text { - Văn hóa và giao tiếp--Việt Nam } \\
\text { - Việt Nam--Điều kiện kinh tế }\end{array}$ \\
\hline
\end{tabular}

Số kiểm soát : 10089

Kho phục vụ : - Kho Sách - Võ Văn Tần [còn 4/4 tài liệu] :... [đặt trước - Kho Sách - Khoa KT-QLC [còn 2/2 tài liệu] :...

2 Kinh tế Việt Nam : thăng trầm và đột phá / Phạm Minh Chính, Vương Quân Hoàng. - Ir Chính trị Quốc gia, 2009. - 554tr ; 22 cm

[Chi tiết]

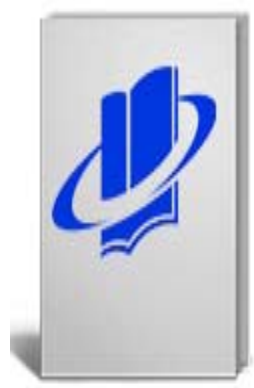

Bộ sưu tập : Sách - Giáo trình

Tác giả chính : Phạm, Minh Chính

Ngôn ngữ : Tiếng Việt

Ký hiệu xếp giá : 338.9597

Lần xuất bản : In lần thứ 1

Nơi xuất bản : Hà Nội : Chính trị Quốc gia, 2009

Mô tả vật lý : 554 tr. ;22 cm

Phụ chú chung : Tủ sách tại Khoa sau đại học có 1 bản. NXB Tri thức

Tóm tắt : Cuốn sách được chia làm 3 phần với trọng tâm nghiên cứu là hệ soát tài chính - tiền tệ. Với hệ thống tư liệu khá phong phú được nguồn trong và ngoài nước trong khoảng thời gian dài, cuốn sácl chấm phá lớn trong bức tranh kinh tế Việt Nam từ khi giành được

Chủ đề : $\quad$ - Kinh tế, Lịch sử

- Việt Nam--Chính sách kinh tế

- Việt Nam--Điều kiện kinh tế

Tác giả bổ sung : Vương Quân Hoàng

Số kiểm soát : 13697

Kho phục vụ : - Kho Sách - Võ Văn Tần [còn 1/1 tài liệu] :... [đặt trước

[Chi tiết] 
3 Các yếu tố thông tin ảnh hưởng đến quyết định mua cổ phiếu của nhà đầu tư cá nhâl Nguyễn Thị Hồng, Vương Quân Hoàng [hướng dẫn]. - Thành phố Hồ Chí Minh : Trường $\mathrm{E}$ Hồ Chí Minh, 2008. - 82tr ; $30 \mathrm{~cm}$

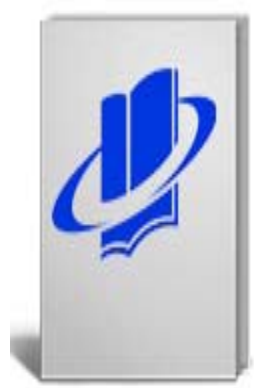

Bộ sưu tập : Luận văn

Tác giả chính : Nguyễn Thị Hồng

Ngôn ngữ : Tiếng Việt

Ký hiệu xếp giá : 658.15

Nơi xuất bản : Thành phố Hồ Chí Minh : Trường Đại học Mở Thành phố Hồ

Mô tả vật lý : 82 tr. ;30 cm

Phụ chú luận văn : Luận văn Thạc sỹ Quản trị kinh doanh

Chủ đề : - Chứng khoán, Thị trường

- Tài chính, Quản trị

Tác giả bổ sung : Vương Quân Hoàng, TS, Hướng dẫn

Số kiểm soát : 21458

Kho phục vụ : - Kho Luậnvăn - Võ Văn Tần [còn 1/1 tài liệu] :...

Tài liệu điện tử :

\begin{tabular}{|c|l|r|}
\hline STT & \multicolumn{1}{|c|}{ Tên file } & Dung lươ \\
\hline 1 & $1786 . p d f$ & $1.76 \mathrm{mb}$ \\
\hline
\end{tabular}

Khảo sát về ESOP trong các công ty cổ phần ở Việt Nam giai đoạn đầu của thị trường ch thạc sĩ / Võ Văn Tùng; Vương Quân Hoàng [hướng dẫn]. - Thành phố Hồ Chí Minh : Trưò phố Hồ Chí Minh, 2008. - 63tr ; 30 cm

[Chi tiết]

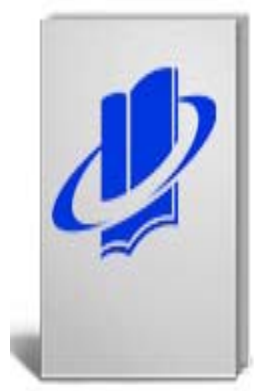

Bộ sưu tập : Luận văn

Tác giả chính : Võ Văn Tùng

Ngôn ngữ : Tiếng Việt

Ký hiệu xếp giá : 658.15

Nơi xuất bản : Thành phố Hồ Chí Minh : Trường Đại học Mở Thành phố Hồ

Mô tả vật lý : 63 tr. ;30 cm

Phụ chú luận văn : Luận văn Thạc sỹ Quản trị kinh doanh

Chủ đề : - Chất lượng, Kiểm soát

- Tài chính, Quản trị

Tác giả bổ sung : Vương Quân Hoàng, TS, Hướng dẫn

Số kiểm soát : 21461

Kho phục vụ : - Kho Luậnvăn - Võ Văn Tần [còn 1/1 tài liệu] :...

Tài liệu điện tử :

\begin{tabular}{|c|c|c|}
\hline STT & \multicolumn{1}{|c|}{ Tên file } & Dung lươ \\
\hline 1 & $1767 . p d f$ & $1.72 \mathrm{mb}$ \\
\hline
\end{tabular}

5 Các phương pháp toán học trong tài chính / Nguyễn Văn Hữu, Vương Quân Hoàng. - In lầ học Quốc gia Hà Nội, 2007. - 181tr ; 24 cm

[Chi tiết]

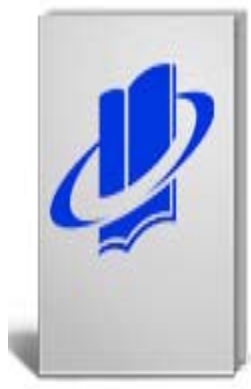

Bộ sưu tập : Sách - Giáo trình

Tác giả chính : Nguyễn Văn Hữu

Ngôn ngũ̃ : Tiếng Việt

Ký hiệu xếp giá : 650.0151

Lần xuất bản : In lần thứ 1

Nơi xuất bản : Hà Nội : Đại học Quốc gia Hà Nội, 2007

Mô tả vật lý : 181 tr. ;24 cm

Tóm tắt : Nội dung: Mô hình rời rạc, bài toán dừng tối ưu và quyền lựa chọ trình vi phân, mô hình Black-Scholes,...

Chủ đề : - Kinh doanh, Toán học

- Toán học

- Ứng dụng, Toán học

Tác giả bổ sung : Vương Quân Hoàng

Số kiểm soát : 40616

Kho phục vụ : - Kho Sách - Bình Dương [còn 3/3 tài liệu] :... [đặt trước 2007. - 497tr ; $24 \mathrm{~cm}$

[Chi tiết]

Bộ sưu tập : Sách - Giáo trình

Tác giả chính : Vương Quân Hoàng

Ngôn ngữ : Tiếng Việt 


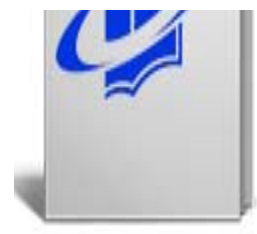

Ký hiệu xếp giá : 650.09597

Lần xuất bản : In lần thứ 1

Nơi xuất bản : Hà Nội : Chính trị Quốc gia, 2007

Mô tả vật lý : 497tr. ;24 cm

Chủ đề : - Hợp tác, Văn hóa--Việt Nam

- Kinh doanh, Nghi thức

- Văn hóa và giao tiếp--Việt Nam

- Văn hóa--Khía canh kinh tế

- Việt Nam--Điều kiện kinh tế

Số kiểm soát : 40659

Kho phục vụ : - Kho Sách - Bình Dương [còn 2/2 tài liệu] :... [đặt trước

7 Các phương pháp toán học trong tài chính / Nguyễn Văn Hữu, Vương Quân Hoàng. - In lẩ Nội, 2007. - 181tr ; 24 cm

\begin{tabular}{|c|c|}
\hline \multicolumn{2}{|c|}{ [Chi tiết] } \\
\hline Bộ sưu tập : & Sách - Giáo trình \\
\hline \multicolumn{2}{|c|}{ Tác giả chính : Nguyễn Văn Hữu } \\
\hline \multicolumn{2}{|c|}{ Ngôn ngũ : Tiếng Việt } \\
\hline \multicolumn{2}{|c|}{ Ký hiệu xếp giá : 650.0151} \\
\hline \multicolumn{2}{|c|}{ Lần xuất bản : In lần thứ 1} \\
\hline \multicolumn{2}{|c|}{ Nơi xuất bản : Hà Nội : Hà Nội, 2007} \\
\hline \multicolumn{2}{|c|}{ Mô tả vật lý : 181 tr. ;24cm } \\
\hline \multicolumn{2}{|c|}{$\begin{array}{l}\text { Tóm tắt : Nội dung: Mô hình rời rạc, bài toán dừng tối ưu và quyền lựa chọ } \\
\text { trình vi phân, mô hình Black-Scholes,... }\end{array}$} \\
\hline \multicolumn{2}{|c|}{$\begin{array}{ll}\text { Chủ đề : } & \text { - Kinh doanh, Toán học } \\
& \text { - Toán học } \\
& \text { - Ứng dụng, Toán học }\end{array}$} \\
\hline \multicolumn{2}{|c|}{ Tác giả bổ sung : Vương Quân Hoàng } \\
\hline \multicolumn{2}{|c|}{ Số kiểm soát : 9546} \\
\hline Kho phục vụ : & - Kho Sách - Võ Văn Tần [còn 15/15 tài liệu] :... [đặt tru \\
\hline
\end{tabular}

Có 7 kết quả tìm được

Sách còn trong kho

Sách đã mượn hết

Sách đang xử lý

Có file Download

Thư viện - Trường Đại học Mở Thành Phố Hồ Chí Minh.

Địa chỉ: 97 Võ Văn Tần - Phường 6 - Quận 3 - TP.HCM

Điện thoại: (028) 39300209 - Fax: (028) 39300085

E-mail: thuviendhm@ou.edu.vn 


\section{Tài liệu tham khảo:}

[1] Vương Quân Hoàng. (2007). Văn minh làm giàu \& Nguồn gốc của cải. Nxb Chính trị Quốc gia, Hà Nội.

[2] Phạm Minh Chính, Vương Quân Hoàng. (2009). Kinh tế Việt Nam: Thăng trầm và Đột phá. Nxb Chính trị Quốc gia, Hà Nội.

[3] Nguyễn Văn Hữu, Vương Quân Hoàng. (2015). Các phương pháp toán học trong tài chính. Nxb Đại học Quốc gia, Hà Nội. 